\title{
Jenis Flora Asing Invasif di Taman Nasional Gunung Gede Pangrango, Jawa Barat
}

\author{
Invasive Alien Species (IAS) in Mount Gede Pangrango National Park, West Java
}

Tahan Uji*, Sunaryo, Erlin Rachman, dan Eka Fatmawati Tihurua

Bidang Botani, Pusat Penelitian Biologi, LIPI

Jl. Raya Jakarta-Bogor Km 46 Cibinong 16911

E-mail: herbogor@indo.net.id*Penulis untuk korespondensi

\begin{abstract}
Ecological study of Invasive Alien Species (IAS) at two altitudes in Mount Gede Pangrango National Park was carried out by using quadrate method. The studied plots located at altitude $1400 \mathrm{~m}$ and $1500 \mathrm{~m}$ a.s.l, in 0.2 ha each. The result shows that 45 species of trees, 77 species of saplings and 48 species of seedlings were recorded. Five species (i.e. Bartlettina sordida, Austroeupatorium inulaefolium, Cestrum aurantiacum, Brugmansia suaveolens and Passiflora suberosa) are catagorized as IAS which threaten the ecosystem and natural species.
\end{abstract}

Key words: Invasive Alien Species, Mount Gede Pangrango National Park, West Java

\begin{abstract}
Abstrak
Penelitian tentang ekologi pada jenis-jenis tumbuhan asing invasive (IAS = Invasive Alien Species) telah dilakukan di dua lokasi yang berbeda ketinggiannya di Taman Nasional Gunung Gede Pangrango dengan menggunakan metoda kuadrat. Pada setiap lokasi dibuat plot seluas 0,2 hektar pada ketinggian $1400 \mathrm{~m}$ dan $1500 \mathrm{~m}$ d.p.l. Hasil penelitian menunjukkan bahwa ditemukan 45 jenis pohon, 77 jenis anak pohon dan 48 jenis semai di kedua lokasi penelitian. Lima jenis di antaranya tercatat sebagai IAS yang dapat mengancam kelestarian ekosistem dan jenis-jenis tumbuhan aslinya. Kelima jenis IAS tersebut adalah Bartlettina sordida, Austroeupatorium inulaefolium, Cestrum aurantiacum, Brugmansia suaveolens dan Passiflora suberosa.
\end{abstract}

Kata kunci: Jenis asing invasif, Taman Nasional Gunung Gede Pangrango, Jawa Barat

Diterima: 30 Juni 2009, disetujui: 12 Januari 2010

\section{Pendahuluan}

Flora asing invasif merupakan jenis-jenis tumbuhan asing yang berkembang dan menyebar di luar habitat aslinya, sehingga mengancam ekosistem, habitat dan jenis tumbuhan asli. Jenis flora asing yang mengadakan invasi tersebut disebut sebagai jenis asing invasif (Invasive Alien Species/IAS). Perpindahan jenis-jenis asing invasif dari habitat aslinya disebabkan antara lain oleh transportasi global, perdagangan bebas dan wisata. Penghalang alami yang semula mampu mengisolasi pergerakan jenis-jenis flora asing invasif, seperti lautan, pegunungan, sungai dan padang gurun, saat sekarang sudah menjadi tidak efektif (Supriyadi, 2007). Dengan demikian introduksi flora asing invasif dari waktu ke waktu mengalami peningkatan (Sunarno dan Rugayah, 1992).

Beberapa kawasan taman nasional di Indonesia diakui juga memiliki problem yang spesifik terhadap masuknya flora asing invasif, misalnya jenis Acacia nilotica di Taman Nasional Baluran, Jawa Timur (Siregar dan Tjitrosoedirdjo, 1999). Taman Nasional ini sebagai area konservasi savana untuk penyediaan makanan herbivor khususnya banteng (Bos javanicus) akan terancam dengan keberadaan Acacia nilotica. Hal serupa juga terjadi di Taman Nasional Pangandaran dan Ujung Kulon, area padang rumput sebagai habitat untuk konservasi banteng sebagian besar juga telah tertutup oleh Chromolaena odorata (Tjitrosemito, 1999). 
Demikian pula di Taman Nasional Gunung Gede Pangrango (TNGGP), Passiflora sp. yang buahnya menjadi makanan mamalia hutan, tumbuh cepat tidak terkontrol merambat dan menutupi tumbuhan lain (Cordon dan Arianto, 2004). Tjitrosoedirdjo (2007) melaporkan bahwa di samping Passiflora sp, ada 2 jenis flora asing invasif lainnya yaitu Austroeupatorium inulaefolium dan Eupatorium sordidum telah tumbuh berkembang di TNGGP. Tjitrosoedirdjo dan Veldkamp (2008) selanjutnya melaporkan bahwa Eupatorium sordidum Less. telah diganti dengan nama yang sah (valid) yaitu Bartlettina sordida (Less.) R.M.King \& H.Rob.

Penelitian ini dilakukan dengan tujuan mengetahui kondisi terakhir vegetasi di TNGGP dalam kaitannya dengan masuknya jenis-jenis flora asing invasif yang berpotensi mengancam kelestarian ekosisitem dan flora asli di kawasan ini.

\section{Metode Penelitian}

Dalam penelitian ini dilakukan analisis vegetasi dengan cara membuat petak pengamatan di dua lokasi yang berbeda ketinggiannya di kawasan TNGGP. Lokasi ini dipilih berdasarkan keberadaan jenis-jenis flora asing invasif yang populasinya melimpah. Lokasi pertama (petak I) dilakukan pada ketinggian $1400 \mathrm{~m}$ dpl pada koordinat $106^{\circ} 44^{\prime}$ 47" LS dan $106^{\circ}$ 59' 39" BT. Lokasi kedua (petak II) pada ketinggian $1500 \mathrm{~m}$ dpl pada koordinat $106^{\circ} 44^{\prime} 50^{\prime \prime} \mathrm{LS}$ dan $106^{\circ} 59^{\prime} 27^{\prime \prime} \mathrm{BT}$. Pada petak I dibuat petak berukuran $40 \mathrm{~m}$ x $50 \mathrm{~m}$ (luas 0,2 ha) dan petak II berukuran $20 \mathrm{~m} \times 100$ $\mathrm{m}$ (luas 0,2 ha). Tiap-tiap petak dibagi menjadi 20 anak petak berukuran $10 \mathrm{~m}$ x $10 \mathrm{~m}$. Pohon dan anak pohon di dalam petak cuplikan diukur diameter batang, dihitung jumlah individu, dan diidentifikasi jenisnya. Identifikasi jenis tumbuhan dibantu dengan menggunakan beberapa buku acuan, antara lain Backer dan van den Brink (1965); Sunarno dan Rugayah (1992). Penentuan jenis dominan didasarkan pada rumus Indeks Nilai Penting (INP) (Cox, 1978; Setiadi, 2005). Penghitungan INP sebagai berikut:

$$
\begin{aligned}
& \mathrm{INP}=(\mathrm{FR}+\mathrm{KR}+\mathrm{DR}) \times 100 \% \\
& \mathrm{FR}=\text { Frekuensi Relatif } \\
& \mathrm{KR}=\text { Kerapatan Relatif } \\
& \mathrm{DR}=\text { Dominasi Relatif }(\mathrm{Cox}, 1978)
\end{aligned}
$$

Penghitungan INP dibagi dalam dua katagori yaitu tingkat pohon (mencakup semua jenis tumbuhan yang berdiameter $\geq 10 \mathrm{~cm}$ ) dan tingkat anak pohon (mencakup semua jenis tumbuhan berdiameter $<10 \mathrm{~cm}$ dan $>2 \mathrm{~cm}$ ).

Untuk mengetahui tingkat semainya maka pada setiap anak petak yang berukuran $10 \mathrm{~m} \mathrm{x}$ $10 \mathrm{~m}$, dibuat plot berukuran $1 \mathrm{~m}$ x $1 \mathrm{~m}$. Plot-plot berukuran $1 \mathrm{~m} \times 1 \mathrm{~m}$ tersebut disusun secara sistematik di kedua petak (petak I dan II). Setiap jenis semai yang ada di dalam plot berukuran 1 $\mathrm{m} \times 1 \mathrm{~m}$ dihitung jumlah individunya.

\section{Hasil dan Pembahasan}

\section{Komposisi Jenis dan Flora Dominan}

Hasil penelitian menunjukkan bahwa pada petak I ditemukan 29 jenis pohon yang tergolong dalam 20 suku dan 25 marga. Pada petak II ditemukan 38 jenis pohon yang tergolong dalam 24 suku dan 32 marga. Jumlah pohon pada petak I dan II secara keseluruhan adalah 45 jenis pohon yang tergolong dalam 26 suku dan 37 marga (Tabel 1). Jumlah anak pohon yang ditemukan pada petak I mencapai 60 jenis tergolong dalam 52 marga dan 34 suku, sedangkan di petak II tercatat sebanyak 62 jenis tergolong dalam 50 marga dan 36 suku. Jumlah jenis secara keseluruhan dari petak I dan II mencapai 79 jenis anak pohon yang tergolong dalam 37 suku dan 61 marga (Tabel 2). Mengacu pada Table 1 dan 2 diketahui bahwa jumlah jenis pohon maupun anak pohon di petak II adalah lebih besar dari pada di petak I. Ini menunjukkan bahwa komposisi jenis pohon dan anak pohon pada petak II relatif lebih besar dari pada petak I.

Pada Tabel 3 diketahui 5 dari 10 jenis pohon yang memiliki urutan nilai penting tertinggi baik di petak I maupun II, masingmasing adalah Musa acuminata, Castanopsis argentea, Toona sureni, Villebrunea rubescens dan Macaranga rhizinoides. Salah satu dari kelima jenis pohon ini yaitu Musa acuminata ternyata memiliki urutan nilai penting tertinggi baik di petak I maupun II. Di samping itu apabila 
mengacu pada Tabel 4 ternyata Pinanga coronata juga memiliki nilai penting yang tinggi bahkan di petak II menempati urutan nilai penting tertinggi nomer dua setelah Bartlettina sordida. Baik Pinanga coronata maupun Musa acuminata, keduanya memiliki kemampuan untuk berkembang biak yang sangat produktif yaitu dengan cara membentuk anakan-anakan di sekeliling tumbuhan induknya.

Tabel 1. Daftar nilai penting jenis pohon di petak pengamatan.

\begin{tabular}{|c|c|c|c|c|}
\hline \multirow{2}{*}{ No. } & \multirow{2}{*}{ Nama Suku } & \multirow{2}{*}{ Nama Jenis } & \multicolumn{2}{|c|}{ Nilai Penting Jenis } \\
\hline & & & Lokasi Petak I & Lokasi Petak II \\
\hline 1. & Araliaceae & "Macropanax dispermum (Blume) O.K. & - & 1,74 \\
\hline 2. & & Brassiopsis glomerulata (Blume) Regel & 9,53 & 14,09 \\
\hline 3. & Caprifoliaceae & Viburnum coriaceum Blume & 3,63 & - \\
\hline 4. & Cyatheaceae & Cyathea contaminans (Wall.ex Hook.) K.Schum. & 3,63 & 1,98 \\
\hline 5. & & C. junghuhniana (Kurze) Copel & 11,79 & 4,54 \\
\hline 6. & Elaeocarpaceae & Elaeocarpus sphaericus (Gaertn.) K.Schum. & - & 2,43 \\
\hline 7. & & E. stipularis Blume & 2,15 & - \\
\hline 8. & Escalloniaceae & Polyosma integrifolia Blume & 2,18 & 5,06 \\
\hline 9. & Euphorbiaceae & Antidesma tetrandum Blume & - & 13,54 \\
\hline 10. & & Glochidion cyrtostylum Miq. & 4,30 & 6,44 \\
\hline 11. & & Macaranga rhizinoides (Blume) M.A. & 9,54 & 43,91 \\
\hline 12. & Fagaceae & Castanopsis argentea (Blume) DC. & 31,43 & 17,54 \\
\hline 13. & & C. javanica (Blume) DC. & 3,17 & 7,23 \\
\hline 14. & & Lithocarpus indutus (Blume) Rehd. & 17,67 & 2 \\
\hline 15. & Flacourtiaceae & Casearia tuberculata Blume & - & 1,75 \\
\hline 16. & & Flacourtia rukam Zoll. \& Merr. & 5,39 & - \\
\hline 17. & Junglandaceae & Engelhardia spicata Lech.ex Blume & 2,50 & 34,43 \\
\hline 18. & Lauraceae & Litsea mappacea (Blume) Boerl. & 2,05 & 2,37 \\
\hline 19. & & Neolitsea cassiaefolia (Blume) Merr. & 1,86 & - \\
\hline 20. & & Persea rimosa (Blume) Zoll. ex Meissn. & 9,36 & 11,21 \\
\hline 21. & Magnoliaceae & Magnolia glauca Blume & 4,17 & - \\
\hline 22. & Meliaceae & Dysoxylum alliaceum Blume & - & 1,75 \\
\hline 23. & & Toona sureni (Blume) Merr. & 11,48 & 12,68 \\
\hline 24. & Moraceae & Ficus grossulorioides Burm.f. & 2,05 & - \\
\hline 25. & & F. ribes Reinw. ex Blume & 4,82 & 4,85 \\
\hline 26. & Musaceae & Musa acuminata Colla & 81,51 & 45,21 \\
\hline 27. & Myrtaceae & Decaspermum fruticosum J.R. \& G.Forst. & - & 4,65 \\
\hline 28. & Pandanaceae & Pandanus furcatus Roxb. & 17,29 & - \\
\hline 29. & Rosaceae & Prunus arborea (Blume) Kalmn. & 2,91 & 3,75 \\
\hline 30. & Rubiaceae & Neonauclea obtuse (Blume) Merr. & - & 3,57 \\
\hline 31. & Rutaceae & Acronychia lauriflora Blume & - & 1,78 \\
\hline 32. & Saurauiaceae & Saurauia blumiana Benn. & 2,81 & 1,93 \\
\hline 33. & & S. pendula Blume & 14,95 & 7,06 \\
\hline 34. & & S. reinwartia Blume & - & 1,75 \\
\hline 35. & Solanaceae & Cestrum aurantiacum Lindl. *) & 2,14 & - \\
\hline 36. & & Solanum verbascifolium $\mathrm{L}$. & 5,22 & - \\
\hline 37. & Staphyllaceae & Turpinia sphaerocarpa Hassk. & 8,25 & 5,70 \\
\hline 38. & Symplocaceae & Symplocos cochinchinensis (Lour.) S.Moore & - & 2,94 \\
\hline 39. & & S. fasciculate Zoll. & 3,16 & 3,84 \\
\hline 40. & & S. costata (Blume) Choisy & - & 1,75 \\
\hline 41. & Theaceae & Pyrenaria serrata Blume & 2,15 & - \\
\hline 42. & & Schima wallichii (DC.) Korth. & - & 4,85 \\
\hline 43. & Urticaceae & Dendrocnide stimulans (L.f.) Chew. & 16,05 & 1,87 \\
\hline 44. & & Villebrunea rubescens (Blume) Blume & 11,02 & 7,13 \\
\hline 45. & Vitaceae & Tetrastigma dichotomum (Blume) Planch. & - & 1,82 \\
\hline
\end{tabular}

Keterangan: *) = Jenis IAS 
Tabel 2. Daftar nilai penting jenis anak pohon di petak pengamatan.

\begin{tabular}{|c|c|c|c|c|}
\hline No. & Nama Suku & Nama Jenis & \multicolumn{2}{|c|}{$\begin{array}{c}\text { Nilai Penting Jenis } \\
\text { Lokasi Petak I Lokasi Petak II }\end{array}$} \\
\hline 1. & Acanthaceae & Strobilanthes blumei Brem. & 7,17 & 101,04 \\
\hline 2. & & S. cernua Blume & - & 2,32 \\
\hline 3. & Aceraceae & Acer laurinum Hassk. & 0,48 & 0,54 \\
\hline 4. & Alangiaceae & Alangium chinense (Lour.) Rehder & 0,49 & - \\
\hline 5. & Angiopteridaceae & Angiopteris evecta (G.Forst.) Hoffm. & - & 5,29 \\
\hline 6. & Annonaceae & Orophea hexandra Blume & 1,48 & - \\
\hline 7. & Araliaceae & Brassiopsis glomerulata (Blume) Regel & 4,58 & 9,34 \\
\hline 8. & & Macropanax dispermum (Blume) O.K. & 2,35 & 4,87 \\
\hline 9. & & Trevesia sundaica Miq. & 3,40 & - \\
\hline 10. & Arecaceae & Calamus adspersus Blume & - & 0,61 \\
\hline 11. & & Daemonorops rubber (Reinw. ex Mart.)Blume & 3,66 & 0,69 \\
\hline 12. & & Pinanga coronata (Blume ex Mart.) Blume & 18,66 & 33,85 \\
\hline 13. & & Plectocomia elongate Mart. ex Blume & 2,30 & 3,44 \\
\hline 14. & Asteraceae & $\begin{array}{l}\text { Austroeupatorium inulaefolium (Kunth) R.M. King \& H. } \\
\text { Robinson *) }\end{array}$ & 39,14 & - \\
\hline 15. & & Bartlettina sordida (Less. ) R.M.King \& H.Rob. *) & 72,20 & 109,02 \\
\hline 16. & & Vernonia arborea Buch - Ham & 0,52 & - \\
\hline 17. & & $V$. cinerea $(\mathrm{L}$.$) Less.$ & 1,13 & - \\
\hline 18. & Caprifoliaceae & Viburnum coriaceum Blume & 1,65 & 2,61 \\
\hline 19. & Cyatheaceae & Cyathea junghuhniana (Kurze) Copel & 15,34 & 1,96 \\
\hline 20. & Elaegnaceae & Elaegnus triflora Roxb. & 0,49 & 1,05 \\
\hline 21. & Escallonaceae & Polyosma integrifolia Blume & 1,25 & 1,79 \\
\hline 22. & Euphorbiaceae & Antidesma tetrandrum Blume & 1,04 & 1,64 \\
\hline 23. & & Glochidion cyrtostylum Miq. & 0,51 & 1,47 \\
\hline 24. & & Macaranga rhizinoides (Blume) M.A. & 0,58 & - \\
\hline 25. & & Omalanthus populneus (Geisel.) Pax. & 0,68 & - \\
\hline 26. & Fagaceae & Castanopsis argentea (Blume) DC. & 0,51 & 1,05 \\
\hline 27. & & C. javanica (Blume) DC. & 1,79 & 1,25 \\
\hline 28. & & Lithocarpus indutus (Blume) Rehd. & - & 1,14 \\
\hline 29. & & L. pseudomoluccus (Blume) Rehd. & - & 1,87 \\
\hline 30. & Flacourtiaceae & Casearia tuberculata Blume & 1,51 & 2,85 \\
\hline 31. & & Flacourtia rukam Zoll. \& Mor. & 1,03 & 1,88 \\
\hline 32. & Lauraceae & Litsea mappacea (Blume) Boerl. & 0,62 & 1,05 \\
\hline 33. & & L. resinosa Blume & 3,55 & 2,42 \\
\hline 34. & & Persea rimosa (Blume) Zoll. ex Meissn. & 3,55 & 2,42 \\
\hline 35. & Magnoliaceae & Magnolia candollii (Blume) H. Keng & 2,45 & 1,22 \\
\hline 36. & Meliaceae & Dysoxylum alliaceum Blume & - & 2,10 \\
\hline 37. & & D. excelsum Blume & 0,50 & - \\
\hline 38. & & Toona sureni (Blume) Merr. & - & 2,71 \\
\hline 39. & Moraceae & Ficus grossularioides Burm. f. & - & 0,61 \\
\hline 40. & & F. ribes Reinw. ex Blume & 1,24 & 2,72 \\
\hline 41. & & F. sinuate Thunb. & - & 1,27 \\
\hline 42. & Musaceae & Musa acuminate Colla & 6,53 & 12,37 \\
\hline 43. & Myrsinaceae & Ardisia fuliginosa Blume & 6,15 & 8,91 \\
\hline 44. & Myrtaceae & Decaspermum fruticosum J.R. \& G. Forst. & 1,11 & 2,26 \\
\hline 45. & & Syzygium antisepticum (Blume) Merr. ex Perry & 0,55 & - \\
\hline 46. & & $S$. rostratum (Blume) DC. & - & 0,51 \\
\hline 47. & Oleaceae & Olea javanica (Blume) Knobl. & 0,48 & - \\
\hline 48. & Pandanaceae & Pandanus furcatus Roxb. & 6,64 & 3,36 \\
\hline 49. & Passifloraceae & Passiflora suberosa L. *) & 1,51 & 3,01 \\
\hline 50. & Rubiaceae & Hypobathrum frutescens Blume & 1,32 & 0,51 \\
\hline 51. & & Lasianthus furcatus (Miq.) Bremek & 0,52 & 1,85 \\
\hline 52. & & L. hirsutus (Roxb.) Merr. & 0,95 & - \\
\hline 53. & & L. inodorus Blume & - & 2,10 \\
\hline 54. & & L. laevigatus Blume & 1,55 & 2,66 \\
\hline
\end{tabular}


Tabel 2. Lanjutan.

\begin{tabular}{|c|c|c|c|c|}
\hline \multirow{2}{*}{ No. } & \multirow{2}{*}{ Nama Suku } & \multirow{2}{*}{ Nama Jenis } & \multicolumn{2}{|c|}{ Nilai Penting Jenis } \\
\hline & & & Lokasi Petak I & Lokasi Petak II \\
\hline 55. & & 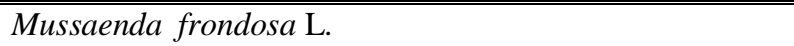 & $1,1,50$ & 2,43 \\
\hline 56. & & Pavetta indica $\mathrm{L}$. & 1,48 & - \\
\hline 57. & Rutaceae & Zanthoxylum scandens Blume & - & 3,36 \\
\hline 58. & Sapindaceae & Mischocarpus fuscescens Blume & 0,47 & 1,33 \\
\hline 59. & Saurauiaceae & Saurauia blumiana Benn. & 0,93 & - \\
\hline 60. & & S. bracteata DC. & 1,38 & - \\
\hline 61. & & S. pendula Blume & 4,60 & 1,56 \\
\hline 62. & & S. reinwartia Blume & 1,00 & 2,24 \\
\hline 63. & Solanaceae & $\begin{array}{l}\text { Brugmansia suaveolens (Humb. \& Bonpl. ex Willd.) } \\
\text { Bercht. \& Persl. *) }\end{array}$ & - & 5,85 \\
\hline 64. & & Cestrum aurantiacum Lindl. *) & 9,26 & - \\
\hline 65. & & Solanum verbascifolium $\mathrm{L}$. & 2,23 & 0,72 \\
\hline 66. & Staphyleaceae & Turpinia sphaerocarpa Hassk. & 1,00 & 3,44 \\
\hline 67. & Symplocaceae & Symplococ cochinchinensis (Lour.) S. Moore & 0,55 & 1,70 \\
\hline 68. & & S. fasciculate Zoll. & 1,04 & 0,99 \\
\hline 69. & Theaceae & Pyrenaria serrata Blume & 1,06 & - \\
\hline 70. & & Gordonea excelsa (Blume) Blume & - & 1,02 \\
\hline 71. & & Schima wallichii (DC.) Korth. & - & 0,63 \\
\hline 72. & Urticaceae & Dendrocnide stimulans (L.f.) Chew. & 7,83 & 0,63 \\
\hline 73. & & Villebrunea rubescens (Blume) Blume & 13,36 & 4,88 \\
\hline 74. & Vitaceae & Tetrastigma sp. & 3,04 & 1,32 \\
\hline 75. & & T. dichotomum (Blume) Planch. & - & 3,56 \\
\hline 76. & Zingiberaceae & Aтотит сосcinium (Blume) K. Schum. & 29,10 & 6,16 \\
\hline 77. & & A. hochreutineri Val. & - & 8,01 \\
\hline 78. & & Nicolaia solaris (Blume) Horm. & - & 6,46 \\
\hline 79. & & Zingiber odoriferum Blume & 0,52 & 0,54 \\
\hline
\end{tabular}

Keterangan: *) = Jenis IAS

Tabel 3. Sepuluh jenis pohon yang memiliki urutan nilai penting jenis tertinggi di petak pengamatan.

\begin{tabular}{clclc}
\hline \hline No. & Nama Jenis Pohon di Petak I & Nilai Penting Jenis & Nama Jenis Pohon di Petak II & Nilai Penting Jenis \\
\hline \hline 1. & Musa acuminate + ) & 81,51 & Musa acuminate + ) & 45,21 \\
2. & Castanopsis argentea + ) & 31,43 & Macaranga rhizinoides + ) & 43,91 \\
3. & Lithocarpus indutus & 17,67 & Elaeocarpus sphaericus & 34,43 \\
4. & Pandanus furcatus & 17,29 & Castanopsis argentea + ) & 17,54 \\
5. & Dendrocnide stimulans & 16,05 & Macropanax dispermum & 14,09 \\
6. & Saurauia pendula & 14,95 & Antidesma tetrandrum & 13,54 \\
7. & Cyathea junghuhniana & 11,79 & Toona sureni + ) & 12,68 \\
8. & Toona sureni + ) & 11,48 & Persea rimosa & 11,21 \\
9. & Villebrunea rubescens +$)$ & 11,02 & Castanopsis javanica & 7,23 \\
10. & Macaranga rhizinoides + ) & 9,54 & Vellebrunea rubescens + ) & 7,13 \\
\hline \hline
\end{tabular}

Keterangan : + ) $=$ jenis dominan di petak I dan II

Tabel 4. Sepuluh jenis anak pohon yang memiliki urutan nilai penting jenis tertinggi di petak pengamatan.

\begin{tabular}{|c|c|c|c|c|}
\hline No. & "Nama Jenis Anak Pohon di Petak I & N Nilai Penting Jenis & Nama Jenis Anak Pohon di Petak II & Nilai Penting Jenis \\
\hline 1. & Bartlettina sordida + ) $*$ ) & 72,20 & Bartlettina sordida + ) ${ }^{*}$ ) & 109,02 \\
\hline 2. & Austroeupatorium inulaefolium *) & 39,14 & Pinanga coronata +$)$ & 33,85 \\
\hline 3. & Amomum coccinium + ) & 29,10 & Musa acumunata & 12,37 \\
\hline 4. & Pinanga coronata + ) & 18,66 & Brassiopsis glomerulata & 9,34 \\
\hline 5. & Cyathea junghuhniana & 15,34 & Ardisia fuliginosa & 8,91 \\
\hline 6. & Villebrunea rubescens & 13,36 & Amomum hochreutineri & 8,01 \\
\hline 7. & Cestrum aurantiacum *) & 9,26 & Nicolaia solaris & 6,46 \\
\hline 8. & Dendrocnide stimulans & 7,83 & Amomum coccinium +) & 6,16 \\
\hline 9. & Strobilanthes blumei & 7,17 & Brugmansia suaveolens *) & 5,85 \\
\hline 10. & Pandanus furcatus & 6,64 & Angiopteris evecta & 5,29 \\
\hline
\end{tabular}




\section{Jenis-jenis Flora Asing Invasif (IAS) dan Potensi Ancamannya}

Dengan mengacu pada Tabel 1, jenis pohon Cestrum aurantiacum merupakan satusatunya jenis pohon asing invasif yang ditemukan di petak pengamatan (petak I). Nilai penting pohon ini relatif masih kecil (nilai penting $=2,14 \%$ ) namun potensi ancamannya di masa mendatang perlu diwaspadai, terlebih lagi besarnya nilai penting pada anak cukup tinggi (Tabel 4).

Selain itu mengacu pada Tabel 4 diketahui bahwa 4 dari 10 jenis anak pohon yang memiliki urutan nilai penting tertinggi baik di petak I maupun II ternyata adalah merupakan jenis-jenis IAS, yaitu Bartlettina sordida, Austroeupatorium inulaefolium, Cestrum aurantiacum dan Brugmansia suaveolens. Bartlettina sordida memiliki urutan nilai penting tertinggi baik di petak I (nilai penting $=72,20 \%$ ) maupun di petak II (nilai penting $=109,02 \%$ ). Ini menunjukkan bahwa keberadaan E. sordidum merupakan salah satu IAS yang memiliki potensi ancaman paling besar di kawasan ini.

Selanjutnya, ditinjau dari urutan besarnya nilai penting setiap IAS yang dijumpai, secara berturut-turut potensi ancaman selanjutnya adalah Austroeupatorium inulaefolium (nilai penting $=39,14 \%$ ), Cestrum aurantiacum (nilai penting $=29,10 \%$ ), dan Brugmansia suaveolens (nilai penting $=5,85 \%$ ). Dari hasil pengamatan di lapangan ternyata keempat jenis IAS tersebut (B. sordida, A. inulaefolium, C. aurantiacum dan $B$. suaveolens) memiliki sistem perbanyakan secara vegetatif yang sangat cepat, yaitu cara pertumbuhan tunas-tunas baru dari akar-akar "adventif" dan dengan setek batang atau ranting.

Di samping itu masih ada 1 IAS lainnya yang ditemukan baik di petak I maupun II, yaitu Passiflora suberosa. Jenis ini tumbuh merambat dan menutupi tajuk-tajuk pohon yang dirambati. Akibat yang ditimbulkan oleh jenis liana ini menghambat pertumbuhan bahkan dapat membunuh jenis tumbuhan lain yang dirambati.

Dari hasil pengamatan terhadap semai dapat ditemukan 35 jenis semai di petak I dan 25 jenis semai di petak II. Tercatat 5 jenis semai yang memiliki jumlah individu paling banyak di kedua petak tersebut, berturut-turut adalah Cyrtandra picta, Procris frutescens, Elatostema nigrescens, Elatostema acuminatum dan Amphineuron terminans. Selanjutnya, semai untuk IAS hanya relatif sedikit ditemukan di kedua petak. Perlu diketahui bahwa biji-biji pada beberapa IAS, antara lain Bartlettina sordida dan Austroeupatorium inulaefolium, hanya mau berkecambah pada kondisi lokasi yang terganggu dan terbuka. Hal ini disebabkan morfologi biji pada kedua jenis IAS ini dipencarkan dengan bantuan angin maka sangat mudah terpencar luas.

\section{Simpulan dan Saran}

\section{Simpulan}

Berdasarkan besarnya Indek Nilai Penting telah ditemukan 5 jenis flora asing invasif, yaitu Bartlettina sordida, Austroeupatorium inulaefolium, Cestrum aurantiacum, Brugmansia suaveolens dan Passiflora suberosa yang berpotensi mengancam kelestarian ekosistem dan keberadaan flora asli di TNGGP.

\section{Saran}

Perlu adanya usaha pengendalian dan pemberantasan pada kelima jenis IAS yang telah mengancam kelestarian ekosistem dan keberadaan flora asli di kawasan TNGGP. Caranya dengan melakukan penanaman kembali di kawasan-kawasan yang telah rusak (terbuka kanopinya) dengan jenis-jenis tumbuhan asli.

\section{Ucapan Terima Kasih}

Ucapan terima kasih disampaikan kepada Kepala Puslit Biologi dan Kabid Botani - LIPI serta Kepala Taman Nasional Gunung Gede Pangrango yang telah memberikan izin penelitian ini, dan kepada Bapak Drs. Suhardjono yang telah membantu menganalisis data vegetasi.

\section{Daftar Pustaka}

Backer, C.A. dan van den Brink, B. 1965. Flora of Java, vol. 2. Noordhoff, Groningen, The Nederlands.

Cordon, A. dan Arianto, W. 2004. Invasive Alien Plant Species in Mount Gede-Pangrango Nature Reserve. J. Gulma Tropika, 2 (2): 75-85. 
Cox, G.W. 1978. Laboratory Manual of General Ecology. New York WM.C.Brown Company Publisher.

Setiadi, D. 2005. Keanekaragaman Jenis Tingkat Pohon di Taman Wisata Alam Ruteng, Nusa Tenggara Timur. Biodiversitas, 6 (2): 118-122.

Siregar, C. dan Tjitrosoedirdjo, S. 1999. Acacia nilotica Invasion in Baluran National Park, East Java, Indonesia. Biotrop Spec. Publ., No. 61.

Sunarno, B. dan Rugayah. 2002. Flora Taman Nasional Gede Pangrango. Herbarium Bogoriense, Puslitbang Biologi - LIPI, Bogor.

Supriyadi. 2007. Model Pertumbuhan Populasi untuk Pengendalian Populasi Akasia Berduri (Acacia nilotica (L.) Willd Ex Del.) di Taman Nasional Baluran. Biota, 12 (3): 161-169.
Tjitrosemito, S.S. 1999. The Establishment of Procecidochares connexa in West Java, Indonesia. A Biological Control Agent of Chromolaena odorata. Biotropia, 12: 19-24.

Tjitrosoedirdjo, S.S. 2007. Notes on the Profile of Indonesian Invasive Alien Plant Species. Biotropia, 14 (1): 62-68.

Tjitrosoedirdjo, S.S. dan Veldkamp, F. 2008. Bartlettina sordida (Eupatorium sordidum) (Compositae), an invasive alien plant species in the Gunung Gede Pangrango National Park, West Java, Indonesia. Fl. Mal. Bull., 14 (3): 172. 